\title{
Carla Fratta (sous la direction de), Littérature et cinéma au Québec 1995-2005
}

Simona Rossi

\section{(2) OpenEdition}

1 Journals

\section{Edizione digitale}

URL: http://journals.openedition.org/studifrancesi/8116

DOI: $10.4000 /$ studifrancesi.8116

ISSN: 2421-5856

\section{Editore}

Rosenberg \& Sellier

\section{Edizione cartacea}

Data di pubblicazione: 1 juillet 2009

Paginazione: 457

ISSN: 0039-2944

\section{Notizia bibliografica digitale}

Simona Rossi, «Carla Fratta (sous la direction de), Littérature et cinéma au Québec 1995-2005», Studi Francesi [Online], 158 (LIII | II) | 2009, online dal 30 novembre 2015, consultato il 13 janvier 2021. URL: http://journals.openedition.org/studifrancesi/8116 ; DOI: https://doi.org/10.4000/studifrancesi.8116

Questo documento è stato generato automaticamente il 13 janvier 2021.

\section{(c) $(7)$}

Studi Francesi è distribuita con Licenza Creative Commons Attribuzione - Non commerciale - Non opere derivate 4.0 Internazionale. 


\title{
Carla Fratta (sous la direction de), Littérature et cinéma au Québec 1995-2005
}

\author{
Simona Rossi
}

\section{NOTIZIA}

CARLA FRATTA (sous la direction de), Littérature et cinéma au Québec 1995-2005, Bologna, Pendragon, 2008, pp. 148.

1 Il volume raccoglie gli atti di un convegno organizzato dal CISQ (Centro Interuniversitario di Studi Quebecchesi) nel dicembre del 2006, che si proponeva di studiare il fecondo e continuo contatto tra cinema e letteratura in ambito quebecchese. In effetti, se è vero che il cinema viene considerato dall'opinione collettiva come un loisir più "popolare" rispetto alla letteratura, la distanza non è invalicabile e lo scambio tra i due generi avviene continuamente. Gli esempi di opere letterarie, e non solo, adattate al cinema non mancano: sono infatti numerosi i romanzi, le biografie, i testi teatrali, che ispirano e stimolano la realizzazione di un film.

Opera collettiva alla quale hanno partecipato ricercatori, scrittori e drammaturghi, Littérature et cinéma au Québec studia in modo approfondito l'adattamento, la rappresentazione e le tecniche cinematografiche che rendono possibile il discorso letterario nel codice espressivo cinematografico. Il volume è composto di dieci saggi: nel primo, André GAUDREAULT e Philippe MARION introducono le problematiche tecniche proprie all'adattamento; nel secondo François BARCELo descrive con grande ironia i vari progetti di trasposizione cinematografica dei suoi romanzi di cui uno soltanto, Cadavres, ha visto la luce; nel terzo Michel Marc BOUCHARD, divenuto sceneggiatore di uno dei suoi testi teatrali, condivide con i lettori quest'esperienza intensa; nel quarto e nel quinto, invece, Marie-Frédérique DESBIENS e Anne DE VAUCHER svolgono una attenta analisi comparativa rispettivamente di due films tratti da Les Rébellions des Patriotes (Quand je 
serai parti ... vous vivrez encore di Michel Brault e 15 février 1839 di Pierre Falardeau), e di due pellicole d'ispirazione biografica (Anne Hébert 1916-2000 di Jacques Godbout; Au-delà des apparences, portarait de Marie-Claire Blais di Suzette Lagacé). Nel sesto saggio, André LOISELLE mostra come il tema dell'alterità quale minaccia dell'identità culturale quebecchese sia amplificato nel cinema dell'orrore; nel settimo Josianne oUELLET offre una ricca panoramica di dati statistici e di dettagli su tale fenomeno di scambio tra cinema e letteratura, fenomeno che si è intensificato notevolemente nell'ultimo decennio, rivelando aspetti nuovi ed inattesi; nell'ottavo Esther PELLETIER ripercorre tutte le tappe che l'hanno condotta all'adattamento cinematografico della vita e dell'opera del pittore canadese René Richard; nel nono Jean-François PLAMONDON studia il delicato simbolismo del film Les Invasions barbares di Denys Arcand, riflettendo sul complesso rapporto dell'epoca contemporanea con la malattia e la morte; nel decimo, infine, lo scrittore Alberto MANGUEL propone la sua originale lettura del film Atanarjuat di Zacharias Kunuk. Completato da una ricca e accurata introduzione della curatrice e da dettagliate bibliografie che seguono ogni saggio, questa raccolta si rivela preziosa per la conoscenza di un aspetto non marginale della cultura quebecchese. 